\title{
FAZER ESCOLA E ESTAR NA CULTURA: O CASO DOS TUPINAMBÁ DE OLIVENÇA, BAHIA
}

\author{
HACER ESCUELA Y ESTAR EN LA CULTURA: EL CASO DE LOS \\ TUPINAMBÁ DE OLIVENÇA, BAHIA
}

José Valdir Jesus de Santana Universidade Estadual do Sudoeste da Bahia - UESB

Clarice Cohn

Universidade Federal de São Carlos - UFSC

\section{Resumo}

Nesse artigo, mesmo diante dos limites que se impõem, posto que não é possível apresentar a densidade dos dados produzidos durante a pesquisa do doutorado a partir da etnografia que realizamos sobre a escola dos Tupinambá de Olivença, entre abril de 2011 e maio de 2012, interessanos lançar pistas acerca dos modos e formas como este povo têm produzido suas escolas e do como, neste processo, são atualizadas relações de parentesco, sentidos para a cultura e o estar na cultura e do como, no limite, a escola atua em defesa do território, no fortalecimento das áreas de retomadas e na luta por sua demarcação.

Palavras-chave: Cultura. Escola. Tupinambá.

\section{Resumen}

En este artículo, mismo delante de los límites que se imponen, puesto que no es posible presentar la densidad de los datos producidos durante la investigación del doctorado a partir de la etnografía que hemos realizado acerca de la escuela de los Tupinambá de Olivença entre abril de 2011 y mayo de 2012, a nosotros nos interesa el lanzamiento de pistas sobre las maneras y formas de cómo 
ese pueblo han producido sus escuelas y de cómo, en ese proceso, son actualizadas las relaciones de parentesco, sentidos para la cultura y el estar en la cultura y del cómo, en el límite, la escuela actúa en defensa del territorio, en la fortificación en las áreas de reanudaciones y en la lucha por su demarcación.

Palabras claves: Cultura. Escuela. Tupinambá.

\section{Introdução}

Em nossa tese de doutorado, defendida no Programa de Pós-Graduação em Antropologia Social da Universidade Federal de São Carlos, desenvolvemos o tema de como a escola atua como produtora e do como é produzida por uma socialidade que, a partir do que os Tupinambá definem como o estar na cultura $^{i}$, possibilita a construção de uma pessoa Tupinambá que estes denominam de forte na cultura. O ser forte na cultura e o debate sobre a cultura aparecem em diversos contextos além da escola e tem sido tratado por diversos autores, em outros contextos etnográficos, a exemplo do Nordeste brasileiro. Dessa forma, segundo Mejía Lara, referindo-se especificamente aos Tupinambá,

Se entendemos o conceito de "estar na cultura" como a maneira como os Tupinambá de Olivença vão definindo as formas que são tornadas indígenas e, simultaneamente, as que os tornam Tupinambá, esse processo tem construído também formas de estar quando se pensam como pessoas indígenas. Essa elaboração de uma definição de pessoa é um processo que ultrapassa as definições de um modo próprio de entender o espaço ou de demarcar certas formas de vida como as expressões de sua indianidade (2012, p.113, grifos nossos).

Nesses termos, estar na cultura não é uma categoria a partir da qual se define o que é o Tupinambá, mas o processo (grifos nossos) em que se traduz sua socialidade para as relações que os definem como indígenas (MEJÍA LARA, 2012, p.68). Nisso, 


\begin{abstract}
"Estar na cultura" é a definição tupinambá em torno da qual se conceitualizam os diferentes campos onde se produz o indígena num lugar só, na qual se objetivam suas formas de vida que ao mesmo tempo se mostram como indígena, e na qual conseguem manter uma definição aberta de sua indianidade, incorporando nesse processo o que vai se tornando o Tupinambá. Um processo do qual participam tanto a coletividade de vivos, como também a coletividade de extra-humanos, os quais se localizados em sua geografia e os tempos guardados em ela os quais são parte de sua socialidade, que em conjunto definem o que é "sua cultura" (MEJÍA LARA, 2012, p.68).
\end{abstract}

Nesse sentido, interessou-nos pensar como o estar na cultura e tornar-se forte na cultura vão sendo produzidos a partir da escola e das relações que ela possibilita e articula, tanto interno quanto externamente; ademais, inspirados pela etnografia de Peter Gow (1997, 2001, 2006, 2010) e Viegas (2003, 2007), buscamos pensar a escola Tupinambá em termos de “idioma de parentesco", na medida em que, através dela (mas não somente) produz-se um tipo de pessoa forte na cultura como reiteram os Tupinambá. Tornar-se forte na cultura implica em compartilhar memórias, afetos, em estar juntos (VIEGAS, 2003, 2007) em produzir cultura e, nesse sentido (e para que isso ocorra), a escola tem se tornado central, na medida em que ela intensifica e amplia relações, tanto internas quanto externas e, do mesmo modo, como dizem os Tupinambá, a escola tem se tornado o lugar da cultura, processo que tem sido observado em outros contextos, como nos demonstra Weber (2006) em sua etnografia sobre os Huni Kuin. Nesses termos, como diversos pesquisadores têm demonstrado, têm ocorrido processos de "indigenização da escola" (BAPTISTA DA SILVA, 2013, p.228), ou formas/mecanismos de sua "domesticação", como demosntrado por Chates $(2011,2013) \mathrm{em}$ relação à escola dos Kiriri e Melo e Giraldin (2012) para os akwe -xerente. Em nossa tese, defendemos que para os Tupinambá escola é cultura e, nesse sentido, o que eles fazem não se limitam a processos de "domesticação" ou "indigenização".

Nesse artigo, portanto, mesmo diante dos limites que se impõem, posto que não é possível apresentar a densidade dos dados produzidos durante a pesquisa do doutorado a partir da etnografia que realizamos sobre a escola dos Tupinambá de Olivença, interessa-nos lançar pistas acerca dos modos e formas como este povo tem produzido suas escolas e do como, neste processo, são atualizadas relações de parentesco, sentidos para a cultura e o estar na 
cultura e do como, no limite, a escola atua em defesa do território e na luta por sua demarcação.

\section{Os Tupinambá dos dias atuais}

De acordo com dados da Secretaria Especial de Saúde Indígena - SESAI (Bahia), em 2011 os Tupinambá contabilizavam 4.486 indivíduos configurando a segunda maior etnia no Estado. Os Tupinambá estão distribuídos em diferentes comunidades que estão dispostas em uma extensão aproximada de 47 mil hectares e que compreende os municípios de Ilhéus, Buerarema e Una. Estes limites geográficos já foram reconhecidos como Terra Indígena e abarcam ambientalmente paisagens muito distintas que se estendem desde a costa litorânea até a região serrana de mata atlântica (ROCHA, 2014).

Olivença, área próxima ao litoral, fora no passado um antigo aldeamento jesuíta, Nossa Senhora da Escada, que preserva até hoje a arquitetura quadricular e a igreja construída em meados de 1700. A maioria das famílias dos nativos foi expulsa da vila durante a primeira metade do século XX, mas algumas conseguiram permanecer e outras acabaram voltando posteriormente, sendo que hoje se constata a presença tanto de moradores indígenas quanto de não indígenas (MARCIS, 2004; VIEGAS, 2007; ROCHA, 2014).

Nossa Senhora da Escada foi elevada à condição de freguesia, cujo termo abarcava os limites da Vila Nova de Olivença, criada por Carta Régia em 1758, embora seu estabelecimento tenha sido concretizado pelo ouvidor Luís Freire de Veras no primeiro semestre de 1759 (MARCIS, 2004, 2013). Segundo Carvalho (2011, p.350), a partir de 1755, as mais populosas aldeias indígenas passaram a ser elevadas a vilas e os religiosos afastados da sua administração, após a expulsão dos jesuítas do Brasil e extinção das ordens religiosas sobre os índios, por Marquês de Pombal. A partir desse momento, passa a vigorar o denominado Diretório Pombalino, que, mesmo tendo sido revogado em 1798, permaneceu oficiosamente em vigor até 1845 , quando foi promulgado o regimento das missões, único documento indigenista geral do império.

Criado, teoricamente, para assegurar o efetivo exercício do princípio da liberdade dos índios, o Diretório se transformou, na prática, em um 
instrumento excessivamente regulamentador, que mais cerceou do que ensejou sua liberdade, ao mesmo tempo que facilitou o avanço de não índios sobre as terras e mão de obra indígenas, dando lugar a toda sorte de coerções (CARVALHO, 2011, p.350).

Com a criação da vila, a então igreja de Nossa Senhora da Escada foi elevada à condição de freguesia. A disposição das residências junto à igreja permaneceu como o centro do governo civil da vila ${ }^{i i}$ formado pela Câmara e pelo diretor dos índios nomeado pelo Governador. A extensão de terras que compunham o aldeamento foi confirmada como termo da vila e patrimônio dos índios e de seus descendentes. Esse modo de estruturação da vila vigorou durante longo tempo e, consequentemente, foi apropriado pelos moradores indígenas, passando a se constituir como espaço de autonomia e de confirmação da identificação étnica (MARCIS, 2013).

No período imperial, com a instituição do poder judiciário centralizado, as câmaras foram transformadas em corporações administrativas, econômicas e legislativas. Entre as atribuições legislativas constava a elaboração e aprovação do Código de Posturas municipal, onde se estabeleciam as normas para o funcionamento do comércio, da utilização/preservação do espaço urbano e dos recursos naturais da vila, além da regulamentação do comportamento e da convivência social. Entre as atribuições econômicas e administrativas constavam: a fiscalização dos funcionários, a realização das eleições e, principalmente, a vigilância para que as posturas fossem obedecidas com a aplicação e o recolhimento de multas aos infratores das normas. $\mathrm{O}$ aumento da população indígena e não indígenas se refletiu na composição da Câmara da vila de Olivença. Nos resultados da votação, nem sempre os escolhidos pelos moradores, constavam identificação étnica, mas alguns negavam explicitamente se declarando "portugueses". Mesmo esses vereadores e demais autoridades locais não podiam desprezar a população indígenas da vila, embora desprezassem a possibilidade de serem equiparados aos índios pela sociedade do entorno e demais autoridades. No entanto, a condição de vila de índios se reproduziu no Império e tornou-se uma prerrogativa de dupla face: era negada, por um lado, devido à extinção do aldeamento, e por outro, era a garantia da própria existência da vila como unidade política e administrativa, uma vez que as terras pertenciam aos descendentes que formavam a maioria da população (MARCIS, 2013, p.3).

Cabe ressaltar, como já nos alertou Marcis (2013), a presença histórica dos Tupinambá em Olivença, o que nos ajuda a compreender a historicidade e a presença dos indígenas em 
Olivença e todo o movimento desencadeado durante o século $\mathrm{XX}$ em torno do reconhecimento étnico e na busca pela demarcação de seu território ancestral.

Mesmo diante da negação, por parte do Estado e dos latifundiários, da existência dos indígenas em Olivença, posto que buscavam se apropriar das terras indígenas, como de fato ocorreu, processo intensificado em fins do século XIX e nas primeiras décadas do século XX, o Diretório dos Índios e o Código de Posturas em Olivença, mesmo que de forma contraditória, acabaram por construir um sentimento de pertença entre os indígenas desta vila, como argumenta Marcis (2013).

\begin{abstract}
Assim como o Diretório dos Índios, o Código de Posturas e outros instrumentos que visaram anular a identificação étnica dos índios de Olivença, também permitiram a utilização da mesma linguagem para a sua afirmação. No processo de reelaboração da identidade étnica, os moradores passaram a se assumir como "índios de Olivença" e eram vistos como tais pelos outros moradores e autoridades. Mesmo as definições generalizantes de "natural" ou "nativo" abarcavam o sentido da origem comum, de práticas culturais próprias e dos direitos tradicionais às terras do antigo aldeamento. Essa identidade foi constantemente reforçada nos discursos dos diretores, vereadores e juiz de órfãos, mesmo sob a concepção negativa e preconceituosa que expressavam ao ressaltarem aspectos como ignorância, ingenuidade (MARCIS, 2013, p.8).
\end{abstract}

No século $\mathrm{XX}$, um dos eventos mais recentes na memória dos Tupinambá é o movimento instigado pelo Caboclo Marcelino (1924-1937), reconhecido como a "Revolta do Caboclo Marcelinoiiì". O indígena resistiu à invasão de Olivença pelas elites, que queriam construir uma ponte entre Ilhéus e Olivença, sobre o Rio Cururipe, no intuito de tornar Olivença numa área de veraneio para as famílias abastadas de Ilhéus (COUTO, 2008; UBINGER, 2012; LINS, 2007). Segundo Couto (2008, p.52),

As incessantes perseguições a Marcelino e seus seguidores tiveram uma imensa repercussão na vida dos tupinambá. As tentativas de combater a presença não indígena na região de Olivença e adjacências geraram uma declarada perseguição não só a Marcelino e seu grupo, mas também a todos os índios de Olivença. O período compreendido entre 1929 a 1936, atualmente referido como $\mathrm{O}$ Massacre pelos índios das comunidades que 
compõem a terra indígena Tupinambá, foi, decisivamente, um período de inúmeras perseguições e torturas infligidas aos Tupinambá, fato que gerou uma deliberada negação (para fora) da sua condição étnica.

Segundo Viegas (2007, p.260), o significado da revolta de Marcelino esteve associado a uma tentativa de contrariar essa usurpação das terras dos índios. A vila estava, pela primeira vez, ocupada pela burguesia fundiária (branca) e administrada por eles contra os interesses dos índios. A relação entre o território da vila e o da mata passa então a ser vital para assegurar a permanência dos Tupinambá na região.

Nas décadas de 1960-1970, já era claro para os índios que aquela ocupação do espaço pelos brancos tinha um efeito devastador, uma vez que inviabilizava a perpetuação dos ciclos de movimentação dos espaços de habitação e começava a restringir as formas de acesso à mata, com as delimitações do espaço. [...] Nesse período em que o equívoco se revela, nas décadas de 1960-1970, os lugares entregues aos brancos nas permutas assumem o sentido pleno de terra. O significado do que é a terra fica então associado à imposição de limites, não apenas no sentido de uma diminuição física do terreno que se habita, mas, principalmente, por impossibilitar a mobilidade cíclica dos espaços de habitação. Esse sentido da imposição de limites para os Tupinambá não pode ser resumido em um dispositivo visual ou geométrico, segundo o qual descreveríamos o ilimitado como um horizonte sem fim, e o limite como uma restrição geométrica desse horizonte. A imposição de limites aproxima-se melhor, nesse âmbito, do sentimento de uma restrição de movimentos. [...] Podemos dizer que os sentidos da terra para os Tupinambá partem da tranquilidade como aspiração e ideal de socialidade (VIEGAS, 2007, p.270-271).

O período de queda da produção do cacau nesta região do sul da Bahia nos idos de $1980^{\text {iv }}$, como consequência da proliferação da praga de "vassoura de bruxa", transformou o cenário da economia local levando à completa falência dos até então ricos proprietários rurais que ostentavam em suas fazendas estruturas físicas grandiosas (ROCHA, 2014). Neste mesmo período, os Tupinambá dão início ao movimento de reorganização interna e empreendem as primeiras ações em busca de reconhecimento étnico por parte do Estado Brasileiro, que serão intensificadas na década de 1990 e nos primeiros anos da década de 2000, a partir da constituição de novas alianças com outros povos indígenas, especialmente com os Pataxó, mas também com instituições indigenistas, a exemplo da Fundação Nacional do Índio FUNAI, do Conselho Indigenista Missionário - CIMI e da Associação Nacional de Ação 
Indigenista - ANAÍ. É dessa forma que dona Genilda (anciã Tupinambá) descreve o início deste movimento e seus desdobramentos:

A gente está no movimento indígena desde o começo; desde 1985 esse movimento começou por aqui, nessa aldeia [referindo-se a Acuípe]; meu pai, Luca Liberato, foi mais Alício para Brasília; aí foram lá representar essa aldeia; foram lá levados por outra pessoa porque eles não sabiam; chegou lá, foram bem recebidos, porque tinha a casa do índio que recebia; aí conversaram com Mário Juruna e apresentaram essa aldeia. Foram três, um homem chamado Paulino, mas esse homem era um homem branco; Mário Juruna disse que o homem branco não poderia ser cacique daqui; quem podia ser cacique daqui era meu pai e o vice cacique o velho Alício. Eles voltam por Salvador e de Salvador chegam aqui; voltaram em Junho; quando chegaram, se reuniram, fizeram festa, comeram muito. Aí meu pai trouxe esse entendimento, mas o pessoal aqui não tinha conhecimento desse movimento indígena. Aí se decidiu em fazer reunião para ir juntando o povo porque o povo não sabe de nada; aí meu pai chegou aqui com seu Alício, fizemos a festa, mas a gente tem de ter o nosso segredo, mas não, eles não tiveram; quando o povo branco soube disso aí, se levantaram contra. Aí foi juntando o povo, dando explicação do que fizeram em Brasília, foi juntando, foi juntando... Depois o pessoal do CIMI chegou, chegaram lá em casa, vieram para entrevistar as pessoas mais velhas, convidou a velha Cicila, mas muitos não queriam contar a história porque tinham receio do que já havia ocorrido com o caboclo Marcelino. Aí começou reunião em Sapucaeira, isso aí já foi puxado por Núbia, aí já estava tendo reunião, para juntar o povo, já estava tendo a missa; o pessoal ia assistir à missa e daí já ia tendo as palestras, o pessoal ia se ajuntando, se ajuntando. O índio é cismado, só gosta de tá no meio quando a coisa é organizada. Teve uma reunião de cacique que fizeram lá em coroa vermelha e eles disseram que a gente tinha que ter um cacique para resolver nossos problemas; aí se reuniu todo mundo para fazer uma eleição. Aí botam dois, Eloísio, mas ele disse, eu não quero ser cacique; mas Valdelice estava querendo ser cacique, aí então falou com o pessoal e a gente votou em Valdelice. Valdelice foi a primeira cacique e tinha uma organização boa, mesmo, porque tinha reunião; sempre tinha reunião aqui, ela vinha com a reunião dela, explicava o que tava passando; também a gente conversava com ela e dizia: Valdelice, você tem que vir na casa da gente porque cacique tem que ouvir o povo e o povo tem que ouvir o cacique e a gente fica trocando palavras. Tem uma hora que o cacique tá errado e a gente já chama o conselho e diz, não é assim, é assim. É assim que a gente anda. Aí ela não importou de vir aqui, aí a gente dizia, Valdelice vá lá, dormir uma noite por lá, pra gente prosar, aí ela não veio, e está devendo 
até hoje. Aí o movimento seguiu e eu não nego, a gente vê umas coisas erradas assim, aí eu disse, eu vou parar até de ir em reunião porque não me sinto bem; aí a gente vai falar o que está errado e já acham que quem está errado é a gente. Aí a gente foi se saindo. Meu marido era vice-cacique dela; aí falei, você vá se saindo desse vice-cacique porque senão você vai entrar num pepino feio aí. Quando o pessoal viu que a situação não estava do agrado de todos, aí foram se separando, foram formando cacique, como hoje tem esse tanto de cacique aí. Acho que essa situação dificulta porque eles são cacique, mas eles para resolverem uma coisa eles têm de sentar em torno deles, conversarem, para verem que direção tomar; tem que ser só uma palavra, não é isso? Aí eles não fazem isso; quando vão acertar uma coisa, um diz uma coisa, outro diz outra, não pode nada dá certo não; na minha mentalidade penso assim. Isso tá dificultando muitas coisas aí.

Esta história tem efeitos nos modos como se tem reconstituído o território, a atuação no movimento indígena, as retomadas ${ }^{\nu}$ feitas pelos Tupinambá hoje em Olivença e a importância da escola neste processo. Diversas etnografias têm sido produzidas nas últimas décadas sobre os Tupinambá, em relação a diferentes temáticas.

A etnografia de Susana Viegas $(2003,2007)$ tem se tornado uma referência importante para pesquisadores, sobretudo entre os antropólogos que continuam a desenvolver pesquisas entre este povo, especialmente diante do esforço empreendido por esta antropóloga no sentido de aproximar as pesquisas produzidas sobre os povos indígenas do Nordeste (os denominados estudos interétnicos) daquelas realizadas no contexto denominado de Terras Baixas da América do Sul (estudos americanistas). Sua etnografia se sustenta em uma antropologia da vida cotidiana, como tem sido praticada e formulada por antropólogos como Peter Gow (1997, 2001), Joana Overing (1991, 1999), Cecília MacCallum (1989,1998), dentre outros, que lhes servem de inspiração. Na realização de seu empreendimento etnográfico, são acionados conceitos como socialidade, comensalidade, convivialidade e micro história que se tornam centrais para a compreensão do parentesco, das relações de gênero, dos afetos, da produção dos lugares que, como defende a pesquisadora, atuariam na produção da pessoa Tupinambá.

Em sua importante etnografia, Viegas (2003, 2007) apresenta alguns princípios ou "disposições estruturantes da socialidade Tupinambá" que, no limite, sintetizam todo o esforço que esta autora faz para compreender a constituição do parentesco e a produção de pessoas entre os Tupinambá. 
As disposições que Viegas elenca como estruturantes da socialidade Tupinambá são cinco: i) "o núcleo reprodutivo mínimo corresponde à relação mãe/casa", traduzido na "importância de "dar sustento" diário"; ii) "a importância do lugar como unidade social primária", posto que tal disposição "reforça, ao mesmo tempo, a importância do lugar como unidade social primária, e o poder estruturante do princípio que influencia a escolha do local de residência pós-marital"; iii) "a tendência agnática"; iv) "o ideal de viver junto em um lugar", mesmo que tal ideal esteja "em constante contraposição com a constelação a favor da tendência agnática"; v) "os atributos da feminilidade hegemônica e da transitividade feminina", que estariam, na prática, "fortemente conectadas com os processos políticos indigenistas e seus correlatos sociais e culturais (VIEGAS, 2007, p.178-180). Segundo Viegas, uma das contribuições específicas de sua etnografia está não só para o debate americanista, mas de forma geral para as novas abordagens do parentesco na Antropologia [...] "é a de mostrar que ao adentrarmos o parentesco podemos estar lidando com assunto de grande profundidade filosófica (normalmente esquecido nessas abordagens), que se prendem com o sentido do tempo na produção da vida social" (VIEGAS, 2007, p.279). Ademais, segundo Viegas (2007, p.285) “[...] o que estou sugerindo, em suma, é que para o debate americanista a aproximação, a reflexão antropológica que lida com identidades performativas pode ser particularmente útil e valiosa exatamente nesse plano que liga a temporalidade às ontogenias ou à historicidade e à experiência vivida".

Em nossa tese, retomamos muito desses conceitos, posto que foram extremamente úteis para pensarmos a relação entre escola, parentesco e o que os Tupinambá ${ }^{\mathrm{vi}}$ tem denominado de estar na cultura.

A etnografia de Patrícia Navarro de Almeida Couto (2008), intitulada Morada dos Encantados: identidade e religiosidade entre os Tupinambá da Serra do Padeiro Buerarema, BA, centra-se na cosmologia deste povo, posto que, segundo a autora, a religiosidade constitui-se como base para a vida dos Tupinambá; nesse sentido, segundo Couto, é a religião que confere força e poder aos índios, favorecendo o enfrentamento das adversidades deste mundo. Ademais, religião praticada pelos Tupinambá da Serra do Padeiro, 
parece sugerir a autora, se constituiria em um marcador diacrítico frente aos Tupinambá de Olivença. Nesse sentido, segundo Couto,

\begin{abstract}
A religião na Serra do Padeiro, tendo o culto aos encantados como principal característica, e tendo em seu Lírio o representante máximo deste culto, se constitui como sustentáculo da comunidade como principal alicerce para os Tupinambá em todos os seus aspectos, inclusive no que concerne a identidade indígena. A afirmação da identidade indígena através da diferença constitui-se em marca sempre presente nos discursos e ações dos Tupinambá da Serra do Padeiro, o ser diferente, o praticar uma religião diferente das demais comunidades Tupinambá e dos outros povos indígenas do Nordeste, confere aos Tupinambá da Serra do Padeiro a possibilidade de se afirmarem através do estabelecimento de fronteiras bastante marcadas, sobretudo com relação aos demais Tupinambá habitantes das comunidades que compõem a área indígena de mesmo nome, seus parentes de praia, oposição frequentemente presente nos discursos dos Tupinambá da Serra do Padeiro quando se colocam como povo das serras em contraposição ao povo da praia, apesar de admitirem que viveram no passado na praia, portanto em Olivença. [...] Entre os Tupinambá da Serra do Padeiro, é praticamente impossível desvincular a luta pela terra, a luta pela afirmação da identidade, da crença nos caboclos-encantados (2008, p.158-160).
\end{abstract}

A etnografia intitulada Os Tupinambá da Serra do Padeiro: religiosidade e territorialidade na luta pela terra indígena, de Helen Catalina Ubinger (2012) trata de aspectos da sociocosmologia já apresentados por Couto (2008), ao mesmo tempo em que busca aprofundá-los e relacioná-los aos processos de territorialização e à construção de uma territorialidade específica, acionados pela memória coletiva acerca do processo histórico e pelas relações interétnicas vivenciados pelos Tupinambá. Nisso, segundo Ubinger (2012), a estruturação social, em termos religiosos, fundamenta-se na alteridade simbólica do grupo étnico, comunicada pela intencionalidade de entidades espirituais, conhecidas como encantados. Desta forma, a autora ilumina a correlação entre etnicidade e religião num processo de visibilidade étnica e política dos membros do território Tupinambá, em que a religiosidade é o sustentáculo do movimento político indígena frente à sua inserção no Estado-Nação, aspecto já abordado por Couto (2008). Ademais, a etnografia busca demonstrar que a religiosidade é o eixo central do modo de vida cotidiano, desempenhando um papel duplo, posto que a organização das rotinas diárias e das atividades agrícolas 
depende da relação com as entidades espirituais e gira em torno das práticas religiosas, da relação com os encantados.

O que diferencia o modo de vida dos Tupinambá da Serra do Padeiro dos modos praticados pelos demais Tupinambá, como aqueles das áreas de Acuípe ou de Olivença, é o fato de que sua autoidentificação está intrinsecamente interligada com a memória social e com os símbolos condensados pelo conceito de "encantado". Na esfera religiosa, as expressões 'caboclo' e 'encantado' são em certa medida intercambiáveis e ambos os termos são usados para referir-se a entidades sobrenaturais na Serra do Padeiro. O principal entre estas entidades é Caboclo Tupinambá, quem, junto com as outras, guia a aldeia na sua vida cotidiana, no ciclo anual e nas lutas atuais. No caso dos Tupinambá da Serra do Padeiro, é claro que existem relações interétnicas, mas a base da sua identidade indígena é mantida pela memória coletiva e ainda reforçada por sua religiosidade (UBINGER, 2012, p.37).

Aline Moreira Magalhães (2010) trata de alguns elementos constitutivos à sociogênese do movimento indígena em Olivença, na década de 1990, a partir das memórias e narrativas de certos atores que fizeram e fazem parte deste processo, no sentido de compreender como certos eventos do passado são vividos no presente por esse conjunto de atores. Muitos dos atores com os quais a etnografia de Aline dialoga são os mesmos que empreenderam o movimento em torno da construção da educação escolar. Dessa forma, segundo Magalhães,

As memórias orais e escritas, provenientes de documentos e das memórias dos moradores mais velhos, respectivamente, foram agregadas pelas lideranças Tupinambá para construir um conjunto de testemunhos sobre as ações por parte de grupos sociais que atingiram diretamente os caboclos de Olivença. Não se trata, absolutamente, de conferir às histórias o estatuto do fabricado artificialmente para garantir bens materiais, a posse da terra e serviços públicos como saúde e educação. Compreender a utilização das narrativas sobre a própria história significa apreender uma das formas por meio das quais os atores sociais, os indígenas de Olivença, começaram a reconhecer a existência de um passado e presente comuns, a partir de um diálogo, propiciado pela mediação e divulgação das educadoras do CAPOREC, prenhe de experiências familiares. Este diálogo proporcionou uma nova articulação das vinte e três comunidades em torno de um objetivo: fazer com que o Estado os reconhecesse como indígenas (2010, p.57-58). 
Segundo a autora, parte dos discursos sobre o passado da população indígena em Olivença relaciona-se às ordens de sofrimento dos atores e grupos sociais envolvidos nos episódios de violências e roubos de suas terras ao longo dos séculos de colonização. A luta pela terra é uma oração porque implica a recuperação de um território perdido pelos antepassados e é por isso que se fazem retomadas (MAGALHÃES, 2010).

A dissertação de Amiel Ernenek Mejía Lara (2012), mesmo não tratando diretamente da escola, ajuda-nos a compreender o que os Tupinambá definem como estar na cultura e que se torna central para a compreensão da educação escolar e do como esta se articula a outras demandas, como a luta pelo território, às investidas na realização de retomadas, que multiplicam escolas, aproximam parentes e atualizam relações que são definidoras da socialidade Tupinambá. Nisso, conforme Mejía Lara (2012, p.68),

"Estar na cultura" é a definição tupinambá em torno da qual se conceitualizam os diferentes campos onde se produz o indígena num lugar só, na qual se objetivam suas formas de vida que ao mesmo tempo se mostrar como indígena, e na qual conseguem manter uma definição aberta de sua indianidade, incorporando nesse processo o que vai se tornando o Tupinambá.

Estar na cultura, como já foi dito, é uma das categorias que traduz suas formas de vida às relações que os definem como indígenas. Assim, "estar na cultura” não é uma categoria que envolve a definição do que é indígena, mas do que se está tornado indígena no processo de definir o que será reconhecido como cultura no contexto de sua relação com os diferentes atores e dos próprios Tupinambá (MEJÍA LARA, 2012).

Daniela Fernandes Alarcon (2013) busca compreender as ações de retomadas levadas a cabo pelos Tupinambá da Serra do Padeiro, posto que, segundo a autora, apesar de as retomadas serem reconhecidas pela literatura antropológica como uma prática disseminada entre os povos indígenas no Brasil, elas não têm sido objeto de estudos detidos. Ademais, segundo Alarcon, as retomadas são mais que "instrumentos de pressão", destinados a fazer com que o Estado brasileiro concluísse o processo administrativo de demarcação da Terra Indígena. Essas formas de ação são parte de uma estratégia de resistência e luta pelo efetivo retorno da terra, categoria engendrada pelos Tupinambá, lastreada em suas concepções territoriais. 
Parece-me, em suma, que o processo de retomada levado a cabo pelos Tupinambá da Serra do Padeiro - e o consequente fortalecimento de sua organização e participação política em espaços que transcendiam a aldeia levavam os indígenas a encadear as formulações sobre sua situação e a de outros grupos em particular a uma crítica de fundo à política indigenista oficial e aos problemas comuns aos diferentes povos que habitam o país. Construir um horizonte de lutas compartilhadas era [e continua sendo] a perspectiva que os Tupinambá tratavam [tratam] de fortalecer. Identificar esse movimento permite pensar as retomadas como suportes em que se coadunam múltiplos sentidos, que podemos começar a deslindar apenas quando consideramos as interpretações históricas, os modos de estar no mundo e os projetos dos Tupinambá. [...] É nesse sentido que me parece um equívoco considerar que o processo demarcatório abarca as retomadas de terras, definidas, segundo essa acepção, simplesmente como um "instrumento de pressão". O horizonte temporal e, sobretudo, político dessas ações é mais amplo. Entendo que as retomadas de terras são parte de uma estratégia de resistência e luta pelo efetivo retorno da terra. Parece-me interessante notar o movimento implicado nessa expressão. Ainda que algumas famílias indígenas tenham sido de fato expulsas da terra, os Tupinambá da Serra do Padeiro compreendiam que, como grupo, haviam permanecido no território, com o encargo de defendê-lo e, no futuro, libertálo: tinham de fazer retornar grandes fatias de terra que foram subtraídas ao território, sequestradas em fazendas. Com isso, ocorreria o retorno da terra em sua integridade e, ao mesmo tempo, o retorno dos índios dispersos. Falavam, assim, de uma história longa, que tem na demarcação da Terra Indígena um de seus capítulos e que continua em construção na aldeia Serra do Padeiro e nas demais partes do território Tupinambá (ALARCON, 2013, p.232-239).

A etnografia de Alarcon lança pistas importantes para pensarmos a relação entre escola, território e retomadas entre os Tupinambá de Olivença, que foi um dos investimentos de nosso trabalho e, dessa forma, em nossa tese, retomaremos muitas das questões abordadas por essa autora.

A tese de doutorado de Cinthia Creatini da Rocha ${ }^{\text {vii }}$ (2014) é uma etnografia sobre as formas e as dinâmicas políticas entre os Tupinambá da Terra Indígena Olivença (Ilhéus, Bahia). Esta aborda os processos que são próprios ao fazer política entre os indígenas e que transborda seus efeitos para a compreensão da territorialidade Tupinambá efetivada, 
sobretudo, nas retomadas e na consolidação de aldeias que se espalham no perímetro da Terra Indígena, como afirma a autora. Ademais, a dimensão da política passa a ser acessada a partir das inter-relações cotidianas, das relações de parentesco, do ato de aproximar e afastar pessoas, enfim, de constituir, romper e novamente estabelecer associações, do produzir cultura e do estar na cultura.

As etnografias de Viegas (2003, 2007), Alarcon (2013), Mejía Lara (2012) e Rocha (2014) são as que dialogam mais diretamente com o tipo de análise que desenvolvemos em nossa tese e, nesse sentido, muitos dos conceitos e questões apresentadas em suas etnografias forma acionados em nosso trabalho. Ademais, à exceção de Alarcon, suas etnografias foram realizadas entre os Tupinambá de Olivença, foco de nossa pesquisa. Mesmo que esses autores não tratem diretamente da escola, suas reflexões iluminam a compreensão acerca desta, uma vez que a construção e a busca por escola entre os Tupinambá estão relacionados a processos mais amplos que envolvem o fazer política, o estar na cultura, à atualização do parentesco e à produção de aparentamento, à construção de um tipo de pessoa forte na cultura e às demandas e lutas em torno do território, às ações de retomadas já que é por meio desses vetores que se instauram formas de socialidades consideradas indígenas, Tupinambá.

\section{Algumas pistas ou porque os Tupinambá querem/fazem escola}

Para Renildo, à época da pesquisa cacique da retomada do Mamão, o resgate da aldeia vai se dando com a construção da escola. Essa fala é central e aponta os diferentes caminhos que explicam o movimento que expande a escola por todo o território, movimento este que experimenta tensões, conflitos, rupturas, já que envolve disputas em torno desta. As escolas, portanto, atuam em defesa do território, já que atraem e fixam famílias nestas áreas, que investirão na produção de uma nova aldeia e de novos lugares, neste movimento em que se "retoma" parentes, território, ao mesmo em que se atua em defesa destes. A luta que os Tupinambá empreendem em defesa do território é a mesma que se volta para produzir e manter suas escolas. Nesse sentido, como sugeriu Susana Viegas, no momento da arguição da tese, "lutar envolve princípios éticos e esforço sobre o mundo" e, do mesmo modo, "lutar está relacionado à ideia de Tupinambá forte na cultura. Estar na cultura passa por experimentar a cultura, através das ligações intersubjetivas". 
Outro aspecto não menos importante é que a escola tem produzido um tipo de enfrentamento mais direto com o Estado, legitimando lutas e produzindo novas demandas. Construir escolas tem sido, inclusive, uma forma de negociar com o Estado, posto que é muito comum ouvir, quando os Tupinambá reclamam a construção de novas Núcleos, a seguinte posição por parte dos que representam o Estado, a exemplo da Secretaria de Educação: "não podemos construir escolas em áreas de retomada, já que o território não foi ainda homologado". No entanto, os Tupinambá continuam construindo e expandindo suas escolas, produzindo novas alianças e fortalecendo o movimento indígena. Antes que o Estado reconhecesse a Escola dos Tupinambá, estes já se empenhavam em sua construção, inclusive como meio de atuar frente ao Estado. Não é à toa quando dizem que "tudo começou com a escola".

Construir escolas implica na construção de novas rotas no território Tupinambá, que além de fazer a escola funcionar, possibilitam a circulação de pessoas entre diferentes comunidades, à visitação entre famílias e, consequentemente, um maior controle sobre o próprio território e maior vigilância sobre áreas e espaços que ainda estão sob o controle de não indígenas. "Com as escolas nucleadas, as crianças já aprendem a conviverem já ali, a se fortalecerem, para quando tiverem que sair para rua, para cidade, já vão com conhecimento da comunidade", afirmou-me uma professora da retomada do Mamão.

No passado, quando tinham que estudar em escolas não indígenas, alguns professores relataram os preconceitos e as dificuldades sofridas. Ter e fazer escola na aldeia, implica em multiplicar a cultura, os valores, o conhecimento, para fortalecer os nossos estudantes, como afirmou a professora Nete. A escola, nesse novo contexto, produz torção e inversão de forças, já que está a serviço dos próprios Tupinambá, inclusive, diante da presença, hoje, de estudantes não indígenas em suas escolas (mesmo que esse fato seja motivo de preocupação).

Outro aspecto importante é que a escola, além de possibilitar a construção de um tipo de pessoa forte na cultura é, também, como nos disse certa vez a professora Nete, um espaço de fortalecimento da identidade do que somos nós povos nativos Tupinambá.

Acrescentamos, ademais, que os Tupinambá não querem uma escola que se limite, apenas, a ensinar a ler e escrever e, dessa forma, o que é considerado uma "boa escola", em 

BAHIA

nossos termos, é uma dimensão valorizada, mas acreditamos que não é a mais importante para os Tupinambá, isso porque, segundo eles, a escolaridade não está só no ler e escrever, está na nossa identidade, está no conhecimento dos nossos valores, está na nossa cultura, como ouvi certa vez de uma professora. Por isso que a escola é valorizada e não ter aula, não ter escola é sempre um problema, sobretudo para os estudantes e suas famílias. As queixas que eles apresentavam iam sempre nessa direção e, por vezes, muitos estudantes abandonavam a escola ou pediam transferência. Não faziam isso porque consideravam a escola ruim ou de qualidade duvidosa (ao menos não eram esses os argumentos recorrentes), mas reclamavam da ausência dos professores, da interrupção das aulas devido a problemas no transporte escolar ou quando estas eram interrompidas durante os períodos mais chuvosos, que inviabilizavam o funcionamento da escola, já que o transporte não conseguia circular pelas comunidades. Não ter escola e aqui nos referimos a não ter aula é um problema para os Tupinambá, inclusive muitos pais veem nisso motivo para tirar seus filhos dela.

O que queremos reiterar é o que constitui "ameaça” à escola ou o que é motivo de preocupação para os Tupinambá não é a suposta "falta de qualidade" do ensino oferecido, como muitos imaginam, inclusive os representantes da Secretaria de Educação, da Diretoria Regional de Ensino, localizada em Ilhéus, que não perdem a oportunidade em lembrar que o “Índice de Desenvolvimento da Educação Básica - IDEB viii da escola indígena é muito baixo", mas sim o não funcionamento dela, isso porque, como defendemos em nossa tesa, é na escola e através dela que os Tupinambá atualizam relações, parentesco, aprendizados, produzem cultura, tornam-se fortes, constroem sentimento de pertença e de luta pela território. As palavras da professora Nete e de José (estudante do ensino médio) são reveladoras nesse sentido:

Muitos querem escola só para aprender a ler e a escrever. Nossa escolaridade não está só no ler e escrever, está na nossa identidade, está no conhecimento dos nossos valores, está na nossa cultura. Muitos não têm o conhecimento disso, não estão se reconhecendo como índio, como índia. Ainda temos muitos parentes que pensam que a escola foi feita para surgir emprego. Ele ainda não está se vendo como um índio; ele ainda não está tendo o conhecimento do que é uma educação diferenciada. Os jovens que vivem mais na zona urbana, muitos têm também esse pensamento, de que a escola serve só para ler e escrever, porque já passam a vivenciar uma outra cultura, já passam a ter conhecimento daquelas músicas, daquelas danças, daqueles negócios esquisitos, feios; aí só querem está cantando aquela música; a partir daí eles acham que a escola é só para ler e escrever e não tem neles mesmo a 
valorização do diferenciado que é muito importante para a vida deles (Nete Entrevista realizada em novembro de 2011, na EEITO).

Eu comecei a estudar na escola indígena desde a quinta série; ia da Tucum para escola; o caminho é ruim, o transporte é péssimo; nós cansamos muito na viagem; a escola é muito boa, gosto de estudar lá; é uma escola que tem uma cultura diferente, língua diferente, tem o português, mas tem o tupi; tem nossa cultura que é ensinada; é muito bom estudar com índio, vou assumindo minha cultura, e aprendendo mais o que ainda não sei; os mais velhos tem muitos conhecimentos que ainda não sei; aí eles vão passando através de cantos, de palestras e nós jovens sempre buscando mais conhecimento para podermos ficar mais interligados no processo de cultura, de retomada, o que é ser índio mesmo, de verdade, viver nossa própria cultura. Ser índio de verdade é assumir sua cultura, lutar por sua terra, se integrar no movimento. Os policiais são respeitados pela fala, nós índios, somos respeitados pelas nossas vestes, pela nossa pintura; um índio bem aculturado [no sentido de viver a cultura] é um índio mais forte, um índio que não assume sua cultura é fraco; o índio que é índio vivencia a sua própria cultura, não se exclui de sua cultura; é uma vergonha um índio não assumir a sua cultura. Eu queria que nossa escola crescesse mais, porque tem poucas salas, queria que tivesse uma sala de informática adequada com internet, um laboratório de ciência, uma quadra melhor (somos índios, mas podemos ser atleta; quem sabe um dia um tupinambá não esteja jogando lá no Brasil, na seleção brasileira); isso é um sonho para o futuro. A qualidade do ensino é boa; eu comparei o meu caderno com o caderno do meu sobrinho que estuda na escola Jorge Calmon (em Olivença), tudo que estava passando em matemática lá estava passando aqui; é bom em termos de educação; mas é ruim, nas vezes que falta a aula, muita aula, quando tem chuva; tem professor que falta também, aí quando as aulas retornam já esquecemos quase tudo que passou na matéria; dificulta bastante, questão de prova, assunto, atrasa muito. Aí a gente fica um pouco perdido nesse meio. (José entrevista realizada em Olivença, em julho de 2011)

"Será que ele vai perder a cultura"? Foi o que ouvi de uma anciã Tupinambá, lamentando a ida de um jovem para a cidade de São Paulo. Foi dela, também, que ouvi a expressão "a letra é a mesma, mas a cultura é diferente" que, levada às últimas consequências, nos possibilita compreender o lugar da escola entre esse povo e do como é possível, através dela, porque é assim que fazem os Tupinambá de Olivença, retomar parentes, produzir parentesco, pessoas fortes na cultura, identidade, numa ação que tem se constituído no mesmo movimento em busca da demarcação ${ }^{\mathrm{ix}}$ e da retomada de seus territórios

Revista RBBA $\mid$ Revista Binacional Brasil Argentina 
ancestrais. Daí porque a escola se multiplica pelo território do mesmo modo que este se expande com a escola.

Da mesma forma que não é possível escola sem o território demarcado, como afirmam, parece-nos que é impossível, atualmente, conceber este território sem escola, posto que tanto um quanto o outro são produzidos e fortalecidos neste movimento. Entre os Tupinambá, fazer escola, fazer política, fazer retomada, produzir escolas em retomadas, estar na cultura, produzir cultura, atualizam e produzem, além de identidade, parentesco, aparentamento; retomam-se parentes "perdidos", que se afastaram da aldeia. Nesse sentido, "as relações políticas e as relações de parentesco seguem por caminhos que se cruzam, visto que acionam princípios similares (de aproximação e afastamento) que dão conta das interações do dia-a-dia" (ROCHA, 2014, p.192).

Se o que o parentesco faz é “produzir parentes”, os Tupinambá produzem parentes, mais fortes na cultura, também na escola. A escola elabora um tipo de pessoa Tupinambá e, dessa forma, alarga e atualiza formas de socialidade para além dos já demonstrados, de forma competente, por Viegas (2007) quando definiu a socialidade Tupinambá e por Mejía Lara (2012), quando refletiu sobre os sentidos do "estar na cultura" para este povo, sem, contudo, terem como espaço privilegiado, ou mesmo abordar com profundidade, a educação escolar entre os Tupinambá. No caso de Viegas, no momento de sua pesquisa, entre 1997 e 1998, os Tupinambá começavam a se organizar e construir estratégias para implantarem, em algumas comunidades, a exemplo de Sapucaeira, uma educação escolar que atendesse às demandas desse povo, no momento em que estes se organizam em torno de seu reconhecimento étnico. Todavia, afirma Viegas,

Além da associação das meninas à mãe e dos meninos ao pai, o segundo contexto constitutivo de socialidade diferenciadoras de gênero é o acesso à escola. [...] A tendência para que os meninos permaneçam nos lugares, onde primeiro vão acompanhando o pai e depois vão sozinhos trabalhar nas roças, e de deixar as meninas saírem dos lugares e irem à escola tem que ser vista, portanto, como uma desvalorização do sistema de ensino para a vida dos homens, não tanto pela instrução que fornece, mas por sua ligação com o mundo exterior. Para os meninos, ficar no lugar e fazer pequenos trabalhos na roça, em vez de ir à escola, significa perpetuar a sua ligação com o espaço da roça $(2007$, p.151-152).

Revista RBBA 
Em sua tese, Viegas $(2003,2007)$ argumenta que os meninos teriam uma tendência maior para permanecerem em seus lugares de origem, trabalhando nas roças da família, enquanto as meninas frequentariam a escola (e seriam mais transitivas), argumento que já não se sustenta a partir de meus dados de campo, pelo menos não depois da inauguração da Escola Estadual Indígena Tupinambá de Olivença (EEITO) no ano de 2006. Atualmente, meninos e meninas, homens e mulheres circulam entre a roça e a escola, entre o litoral e o interior do território para irem à escola; como já afirmado, a escola intensifica e constrói novas relações, aproxima parentes, fortalece identidades, constrói cultura, compartilha memória e afetos, produz liderança, caciques e, no limite, constrói parente a partir do que eles denominam do estar na cultura e do tornar-se forte na cultura ${ }^{x}$.

Outro aspecto importante é que ao se expandir pelo território, através dos processos de nucleamento, a escola produz o mesmo efeito, de aproximação e de fortalecimento, da produção de parentesco e da cultura, na medida em que vai aproximando, intensificando relações, fortalecendo e produzindo cultura, "retomando" e produzindo parentes.

Os Tupinambá afirmam insistentemente que a escola é o lugar onde se constrói cultura, o lugar da cultura, visto que nas comunidades, a cultura tem se perdido, enfraquecido. Como sugerem, na e pela escola são construídas pessoas fortes, guerreiras, fortalecidas pela história e memória das lutas que os antepassados empreenderam para se manterem e defenderem o território, mas também pelo movimento que aproxima parentes, indígenas e não indígenas que frequentam a escola em Sapucaeira e os Núcleos, na medida em que "a escola é um patrimônio onde se juntam todas as comunidades", como ouvi de uma professora.

A escola impregna os Tupinambá de força, produz corpos aparentados e tem sido um dos vetores acionados na produção de pessoas sabidas, o que implica na valorização e vivência da cultura, da tradição, mas também na compreensão de que é preciso capturar a leitura e a escrita, na medida em que, como ouvi de um estudante, é preciso ter índio estudado para cuidar dos parentes. Tornar-se sabido, no sentido dado pelos Tupinambá, é condição para manejarem novas relações, tanto internas quanto externas, construírem novas parcerias com instituições e coletivos em benefício do próprio povo. 
Nesses termos, fazer política, ação acompanhada do fazer escola, implica em produzir e atualizar o parentesco, em sair em defesa do território, da escola, da cultura, do estar na cultura, de um modo de vida considerado Tupinambá. É por isso que a escola vai se tornando a "base de tudo", ajudando "no resgate da aldeia". É por isso que as escolas acompanham as retomadas, as comunidades, as aldeias, fortalecendo-as e sendo fortalecidas.

Resgatar e retornar à aldeia, ao território, acaba por nos dizer muito acerca do que os Tupinambá definem como estar na cultura. Retornar, resgatar e retomar, inclusive para aqueles que conseguiram permanecer na TI e para os que a ela retornam, é condição para restabelecer as condições, que estavam perdidas, para criar socialidade, para se viver na cultura e produzir cultura para si, na relação com os parentes, com os encantados, com espaços de memória. O retorno ao território é em duplo sentido: é no sentido do retorno, da ocupação e de sua defesa, especialmente, daqueles que foram forçados a sair do território, quando perderam suas terras, mas também no sentido de "fazer o território retornar", pelas ações de cuidado, de recuperação de áreas degradadas, que reconectam humanos e não humanos.

A expressão é no juízo da gente que a gente tem, porque viu o que se passou, ouvida de uma anciã, tem possibilitado, através da valorização das histórias e memórias que estes carregam que muitos Tupinambá acessem e atualizem sentidos para estar na cultura, que reverberam na produção de corpos fortalecidos de estudantes, professores, lideranças, caciques, etc, posto que esta (a cultura) precisa ser incorporada, colocada no corpo, a partir das histórias e da memória, da pintura, do ritual, da circulação e do aprendizado no território, do habitar em áreas de retomada. A escola tem construído esse movimento, que não é nunca homogêneo e, ao mesmo tempo, é construtora de novas demandas, alianças, aproximações e afastamento e de novos sentidos. Segundo Carvalho (2007, p.31) "a educação indígena não pode, absolutamente, ser dissociada da demarcação e integridade dos territórios, do atendimento à saúde, nutrição e preservação ambiental, mediante políticas e práticas continuadas, informadas e avaliadas pelos próprios índios”.

A escola Tupinambá tem possibilitado a construção de relações mais simétricas com não indígenas e instituições que se tornam parceiras para os mais diversos fins, a exemplo da ONG Thidewá, com projetos voltados para a construção de vídeos sobre as aldeias e livros sobre a história dos Tupinambá; a Universidade Estadual do Sudoeste da Bahia, com as ações que têm sido desenvolvidas pela professora $\operatorname{Dr}^{\mathrm{a}}$ Consuelo Paiva, no ensino na língua

\begin{tabular}{l|l} 
Revista RBBA & Revista Binacional Brasil Argentina
\end{tabular} 
Tupinambá; com a Universidade Estadual de Santa Cruz que tem organizado, anualmente, em parceria com os Tupinambá, a Seminário "Índio Caboclo Marcelino", que nos últimos anos tem sido coordenado pelo professor Dr. Carlos José, desta mesma Universidade; com a Universidade do Estado da Bahia e do Instituto Federal da Bahia, através da Licenciatura Intercultural Indígena, que tem constituído grupos de pesquisadores indígenas que realizam pesquisas sobre o próprio povo, além da FUNAI e outas instituições.

Ademais, a escola tem produzido uma nova geração de lideranças, especialmente de estudantes, que tem se voltado para a cultura, como ouvi de professores Tupinambá; esses estudantes, como pude acompanhar, têm se articulado no sentido da cobrança $e$ do fortalecimento da cultura na escola, como ouvi de alguns; começam a acompanhar, de forma mais sistemática, as ações do corpo diretivo da escola e a se envolver na tomada de decisões. Acompanhei uma reunião em Sapucaeira, em abril de 2012, em que estes estudantes cobravam da direção providências frente a ausência do professor às aulas de cultura e, do mesmo modo, cobravam a presença do coordenador indígena na escola; questionavam a direção diante da indefinição do horário das aulas, posto que, segundo eles, "chegavam à escola para ter aula de um professor e encontravam outro"; reclamavam sobre professores que entravam em sala de aula despreparados, especialmente os que tinham que substituir um colega, às presas, diante de sua ausência. Esse grupo de alunos tem sido acionado a participar de intercâmbios com escolas de Ilhéus e Una, espaços de quilombo em Itacaré e em eventos da Universidade Estadual de Santa Cruz.

Os Tupinambá resistem, os estudantes e professores resistem e produzem, na luta diária, inclusive para chegar à escola, sentidos sobre a luta, resistência indígena, dificuldades, sobre sua cultura e nisso constroem seus projetos de presente e futuro. Ademais, a escola, ao produzir novos cargos, postos de trabalho, possibilita que muitos Tupinambá permaneçam no território e, com isso, possam cuidar dos parentes, de modo a conciliar e atualizar "formas tradicionais de cuidado", como já reveladas por Viegas (2007), através da comensalidade, convivialidade, co-residência, da produção de afetos, de lugares e memórias com os novos agenciamentos que a escola tem construído. Não seria exagero afirmar que a escola tem sido vetor para tudo isso ou, como sugeriu Antonella Tassinari, no momento de arguição da tese, 
de forma apropriada e provocativa (não teremos como desenvolver, no momento, sua provocação), a escola tem sido e construída entre os Tupinambá, em termos de uma "perspectiva tupi" ou no sentido da Tekoá Guarani (lugar onde se realiza o modo de ser e estar com os parentes de forma adequada), "variações de um modo de ser que se realiza em diferentes lugares".

Por fim, o que defendemos é que para os Tupinambá de Olivença escola é cultura ${ }^{\mathrm{xi}} \mathrm{e}$, nesse sentido, o que eles fazem não é um processo de "indigenização" ou mesmo de "domesticação", como têm sugerido alguns autores, a exemplo de Baptista da Silva (2013) e Chates (2011). É na escola e através dela que se produzem diferenças, pessoas, parentesco, a própria cultura, que precisa ser constantemente atualizada, relacionada e experimentada. É por isso que, obstinadamente, os Tupinambá querem e desejam a cultura na escola.

\section{Considerações finais}

Os Tupinambá fazem escola para resistirem e resistem fazendo escola. Estudar é resistir. Possibilidade, inclusive, para se manter no território, cuidando dos parentes.

Estudar é como fazer retomada, em duplo sentido: é resistência, diante dos perigos, das dificuldades que se enfrenta para chegar à escola. Alguns desses perigos são muito reais, sobretudo quando se instaura tensões mais agudas com os fazendeiros, dentro do próprio território. Ir à escola, nessas circunstâncias, é sempre perigoso. Por outro lado, estudar é “retomar", de forma sempre atualizada, através do que se aprende na e pela escola, a história dos antepassados, suas lutas, resistências; é produzir e estar na cultura como temos afirmado.

\section{Referências}

ALARCON, D. F. O retorno da terra: As retomadas na aldeia Tupinambá da Serra do Padeiro, sul da Bahia. 2013, 343f. Dissertação (Mestrado em Estudos Comparados sobre a América) - Instituto de Ciências Sociais, Programa de Pós-Graduação em Estudos Comparados Sobre as Américas, Universidade de Brasília, Brasília, 2013.

BAPTISTA DA SILVA, S. Cartografia sociocultural de espaços e práticas educativos ameríndios: refletindo sobre a indigenização da escola. Espaço Ameríndio, Porto Alegre, v. 7, n. 2, p. 227-238, jul./dez. 2013. Disponível em: file:///C:/Users/PC/Downloads/43550179381-1-PB.pdf; Acesso: maio de 2014. 
CARVALHO, M. R. G. de. "Índios do sul e extremo sul baianos: Reprodução demográfica e relações interétnicas". In: OLIVEIRA FILHO, J. P. de (org.). A presença indígena no Nordeste: Processos de territorialização, modos de reconhecimento e regimes de memória. Rio de Janeiro: Contra Capa, 2011.

Os índios pedem passagem. Ciência e Cultura. São Paulo, v. 59, n. 2, p. 29-31, 2007. Disponível em: http://cienciaecultura.bvs.br/scielo.php?script=sci_arttext\&pid=S000967252007000200014; Acesso: abril de 2012.

O Monte Pascoal, os índios Pataxó e a luta pelo reconhecimento étnico. Caderno CRH, v. 22, n. 57, p. 507-521, 2009. Disponível em: http://www.scielo.br/scielo.php?pid=S0103-

49792009000300006\&script=sci_abstract\&tlng=pt; Acesso: março de 2014.

CHATES, T. de J. A domesticação da escola realizada por indígenas: uma etnografia histórica sobre a educação e a escola Kiriri. 2011, 181f. Dissertação (Mestrado em Antropologia) - Programa de Pós-Graduação em Antropologia, Universidade Federal da Bahia, Salvador, 2011.

A domesticação da escola na perspectiva Kiriri. In: César, A. L. S.; COSTA, S. L. (Orgs.). Pesquisa e escola: experiências em educação indígena na Bahia. Salvador: Quarteto, 2013.

COUTO, P. N. de A. Morada dos encantados: Identidade e religiosidade entre os Tupinambá da Serra do Padeiro - Buerarema, BA. 2008, 169f. Dissertação (Mestrado em Ciências Sociais), Programa de Pós-Graduação em Ciências Sociais, Universidade Federal da Bahia, Salvador, 2008.

GOW, P. O parentesco como consciência humana: o caso dos piro. Mana - Revista de Antropologia Social, vol.3, n.2, p. 39-65, 1997. Disponível: http://www.scielo.br/scielo.php?script=sci_arttext\&pid=S0104-93131997000200002; Acesso: julho de 2010.

. Da etnografia à história: "Introdução" e "Conclusão" de of Mixed Blood: kinship and history in Peruvian Amazônia. Cadernos de Campo, n. 14/15, p. 197- 226, 2006. Disponível em: http://www.revistas.usp.br/cadernosdecampo/article/view/50107; Acesso: julho de 2010.

¿Podia ler Sangama?: sistemas gráficos, linguaje y shamanismo entre los Piro (Perú Oriental). Revista da FAEEBA - Educação e Contemporaneidade, Salvador, v. 19, n. 33, 2010.

Of Mixed Blood: kinship and history in Peruvian Amazônia. Oxford: University Press of Oxford, 2001.

LINS, M. da S. Os vermelhos nas terras do cacau: A presença comunista no sul da Bahia (1935-1936). 2007. 255f. Dissertação (Mestrado em História) - Faculdade de Filosofia e Ciências Humanas, Universidade Federal da Bahia, Salvador, 2007. 
MAGALHÃES, A. M. A luta pela terra como "oração": Sociogênese, trajetórias e narrativas do "movimento" Tupinambá. 2010, 151f. Dissertação (Mestrado em Antropologia Social), Programa de Pós-Graduação em Antropologia Social, Museu Nacional, Universidade Federal do Rio de Janeiro, Rio de Janeiro, 2010.

MARCIS, T. $\boldsymbol{A}$ "hecatombe de Olivença": Construção e reconstrução da identidade étnica 1904. 2004. 163f. Dissertação (Mestrado de História), Programa de Pós-Graduação em História Social, Universidade Federal da Bahia, Salvador, 2004.

A integração dos índios como súditos do rei de Portugal: uma análise do projeto, dos autores e da implementação na Capitania de Ilhéus, 1758-1822. 2013, 309f. Tese (Doutorado em História) - Programa de Pós-Graduação em História Social, Universidade Federal da Bahia, Salvador, 2013.

MCCALLUM, C. Alteridade e sociabilidade kaxinauá: perspectivas de uma antropologia da vida diária. Revista Brasileira de Ciências Sociais. vol. $13 \mathrm{n} . \quad 38, \quad \mathrm{~s} / \mathrm{p}, \quad 1998.2$ Disponível http://www.scielo.br/scielo.php?script=sci_arttext\&pid=S0102-69091998000300008; Acesso em: maio de 2009.

Gender, Personhood and Social Organization amongst the Cashinahua of Western Amazônia. Londres: London School of Economics, University of London, 1989.

MEJÍA LARA, A. E. "Estar na cultura": os Tupinambá de Olivença e o desafio de uma definição de indianidade no Sul da Bahia. 2012, 153f. Dissertação (Mestrado em Antropologia Social), Programa de Pós-Graduação em Antropologia Social, Universidade Estadual de Campinas, Campinas, 2012.

MELO, V. M. C. de; GIRALDIN, O. Os akwe -xerente e a busca pela domesticação da escola. Revista Tellus, ano 12, n. 22, jan./jun, p. 177-199, 2012. Disponível em: http://www.tellus.ucdb.br/index.php/tellus/article/view/279; Acesso: agosto de 2013.

OVERING, J. Elogio do cotidiano: a confiança e a arte da vida social em uma comunidade amazônica. Mana - Revista de Antropologia Social, Rio de Janeiro, v. 5, n. 1, p. 81107, 1999. Disponível em: http://www.scielo.br/scielo.php?script=sci_arttext\&pid=S010493131999000100004; Acesso: setembro de 2010.

OVERING, J. "A estética da produção: o senso de comunidade entre os Cubeo e os Piaroa". Revista de Antropologia, n. 34, p 7 - 33, 1991. Disponível em: http://www.revistas.usp.br/ra/article/view/111249; Acesso: setembro de 2010.

PARAÍSO, M. H. Marcelino José Alves: de índio a caboclo, de "Lampião Mirim" a comunista, uma trajetória de resistência e luta no sul da Bahia, 2009. Anais do XXV Simpósio Nacional de História. Salvador, Bahia, 2009.

ROCHA, C. C. da. "Bora vê quem pode mais": Uma etnografia sobre o fazer política entre os Tupinambá de Olivença (Ilhéus, Bahia). 2014. 303f. Tese (Doutorado em Antropologia Social) - Programa de Pós-Graduação em Antropologia Social, Universidade Federal de Santa Catarina, Santa Catarina, 2014.

SANTANA, J. V. J. de. "A letra é a mesma, mas a cultura é diferente": a escola dos Tupinambá de Olivença. 2015. 241f. Tese (Doutorado em Antropologia Social) - Programa de Pós-Graduação em Antropologia Social, Universidade Federal de São Carlos, São Carlos, 2015. 
UBINGER, H. C. Os Tupinambá da Serra do Padeiro: Religiosidade e territorialidade na luta pela terra indígena. 2012, 189f. Dissertação (Mestrado em Antropologia), Programa de Pós-Graduação em Antropologia. Universidade Federal da Bahia, Salvador, 2012.

VIEGAS, S. de M. Socialidades Tupi: Identidade e experiência entre os índios-caboclos (Bahia/Brasil). 2003, 423f. Tese (Doutorado em Antropologia), Faculdade de Ciências e Tecnologia, Universidade de Coimbra, Coimbra/Portugal, 2003.

Terra Calada: Os Tupinambá na Mata Atlântica do sul da Bahia. Rio de Janeiro: 7Letras, 2007.

WEBER, Ingrid. Um copo de cultura: os huni kuin (Kaxinawá) do rio humaitá e a escola. Acre: EDUFAC, 2006.

\section{Notas}

\footnotetext{
${ }^{i}$ Nesse texto, expressões e termos que se apresentam em itálico, correspondem às perspectivas nativas. Nos casos em que não se relacionarem a estas perspectivas, explicitaremos no texto.

ii A condição de vila impôs a reorganização administrativa e implicou a nova organização social, orientada pela legislação colonial e posteriormente após a independência, imperial. As relações sociais passaram a ser regulamentadas por um Código de Posturas e não mais pelos costumes e tradições de cada povo. A legislação provincial no Império determinava que em todas as vilas e cidades fosse elaborado e aprovado pelos vereadores de um código de posturas, seguindo o modelo produzido pelo Governo da Província. Orientava-se, no entanto, que adotassem os artigos mais condizentes com a realidade local, levando em conta suas especificidades. [...] Em Olivença, o Código de Posturas em vigor no ano de 1859 era composto por 15 artigos, (grifos nossos) que regulamentavam a vida social urbana, o comércio e a produção. As resoluções estabelecidas proibiam, por exemplo, atirar com armas de fogo sem licença "dentro da vila por serem as casas de palha"; proibiam a criação de porcos e a manutenção de animais bravos soltos e obrigava "trazer as frentes das casas limpas" (MARCIS, 2013, p. 6).

iii Para maiores informações sobre esse episódio, vê os trabalhos e Lins (2007), Paraíso (2009) e Couto (2008).

iv "A crise econômica de 1929 reduziu drasticamente tanto o preço do cacau quando o seu consumo (Santos, 2000:40 apud Silva e Leão, 1987). Algumas políticas implementadas pelo Estado tentaram subsidiar a continuidade da produção: i) a criação, pelo governo da Bahia, em 1931 do Instituto de Cacau da Bahia (ICB) para fornecer assistência técnica e creditícia aos produtores; ii) da Comissão Executiva do Plano de Lavoura Cacaueira (CEPLAC) em 1957 pelo governo federal, instituição dedicada para industrialização do produto e diminuição da dependência do mercado externo. Tais políticas não foram suficientes para salvar a monocultura cacaueira de Ilhéus. Em 1985 ocorreu uma nova crise acarretada pela dependência do mercado externo, a crise institucional da CEPLAC, e aparecimento da vassoura-de-bruxa em grandes plantações. Em consequência houve queda de produção, desemprego em massa da população rural, e um movimento migratório campo-cidade. Neste contexto, a estratégia de intervenção encontrada por parte de diversas entidades de Coaraci, instituições religiosas, culturais e políticas, notadamente a FASE, instalada em Itabuna, foi a assessoria organizativa aos sindicatos e entidades de trabalhadores, no sentido de negociar com os proprietários melhores salários e condições de trabalho, proporcionar novas alternativas de fontes de renda para as famílias residentes no meio rural, e a criação de um programa de alfabetização de adultos" (MAGALHÃES, 2010, p. 33).

v "Retomadas" consistem em processos de recuperação, pelos indígenas, de áreas por eles tradicionalmente ocupadas, no interior das fronteiras da Terra Indígena - TI, e que se encontravam em posse de não índios. São ações encabeçadas por um cacique, algumas de suas lideranças e famílias indígenas que ao identificarem uma área improdutiva ou abandonada dentro da TI investem na ocupação territorial da mesma (CARVALHO, 2009; MEJÍA LARA, 2012; ALARCON, 2013; ROCHA, 2014; SANTANA, 2015).

vi Outro campo de estudo muito acionado e que tem produzido importantes reflexões acerca da própria região cacaueira, parte da História Regional e de pesquisas realizadas por estudiosos da Universidade Estadual de Santa
} 

BAHIA

Cruz, a exemplo de Terezinha Marcis, especialmente sua dissertação de mestrado, intitulada "A Hecatombe de Olivença: construção e reconstrução da identidade étnica - 1904 (2004)" e que está diretamente relacionada à história dos Tupinambá nos primeiros anos do século XX. Sua tese de doutorado, intitulada "A integração dos índios como súditos do rei de Portugal: uma análise do projeto, dos autores e da implementação na capitania de ilhéus, 1758-1822" dá continuidade ao debate sobre a presença indígena na Capitania de Ilhéus, numa perspectiva mais diacrônica e alargada. Como a autora afirma, "a curiosidade em conhecer mais profundamente a origem e a dinâmica política e social das vilas de índios de Barcelos, Santarém e Olivença, situadas no distrito da Comarca de Ilhéus, sul da Bahia, foi instigada pela pesquisa do meu mestrado, cujo foco girou em torno do personagem, o coronel Raimundo Nonato do Amaral, nativo de Olivença e identificado como sendo de origem indígena. $\mathrm{O}$ coronel foi incriminado e julgado como mentor intelectual e mandante de um crime ocorrido em 1904 que vitimou sete membros de um grupo político, de oposição ao coronel, e que se proclamaram eleitos para os cargos de intendente e vereadores da então Intendência da vila de Olivença. O grupo ocupou a Igreja de Nossa Senhora da Escada e foi cercado por mais de cem pessoas - moradores e aliados do coronel Nonato Amaral. Essa ação culminou com um tiroteio e a morte dos sete membros do grupo da oposição. Na busca por detalhes da biografia do coronel indígena, deparamo-nos com sua origem familiar, cujo pai era português e a mãe índia de Olivença. Seu pai atuou como comerciante, diretor dos índios e vereador da câmara da vila no período imperial brasileiro. O coronel Nonato, herdeiro político e das posses do pai, continuou como chefe político de Olivença, que foi elevada à condição de intendência quando da reestruturação legislativa do regime republicano do Brasil. Os moradores de Olivença se identificavam como indígenas e/ou nativos, eram eleitores e vereadores eleitos desde o Período Colonial e, pelo menos, em três ocasiões, se referiram à carta régia do rei de Portugal que criou a vila ao extinguir o aldeamento. O longo processo de desestruturação da autonomia administrativa de Olivença culminou com as reformas imperiais dirigidas aos povos indígenas que extinguiu os aldeamentos e promoveu a distribuição de lotes de terras das aldeias e vilas aos índios considerados integrados na sociedade dominante e aos demais interessados. O mesmo processo ocorreu nas duas outras vilas que existiram até as primeiras décadas do Império Brasileiro, existência comprovada pelos manuscritos das câmaras guardados no Arquivo Público da Bahia: de Barcelos, período de 1823-1867 e 1833-1889; de Santarém, 1823-1848, e de Olivença 1823-1888. Esses maços contêm a relação nominal de alunos índios, crioulos e mamelucos que frequentavam a escola da "Diretoria dos Índios", denúncias, abaixo-assinados, atas das eleições, descrições das vilas e reivindicações de cargos públicos. Essa síntese desvela a presença de uma população identificada como indígena e moradora das três vilas/intendências que mantiveram durante séculos essa identificação étnica, mesmo vivendo um processo de dispersão e miscigenação. Esses moradores desafiaram os prognósticos das políticas integracionistas decretados desde o Período Colonial, especialmente, pelo Diretório dos Índios. Nessa perspectiva e fundamentada em uma bibliografia que aborda os povos indígenas e a Capitania de Ilhéus, se delineou a proposta de conhecer o processo de implantação do Diretório e as estratégias usadas pelos índios impactados para manterem suas terras e identificação étnica. A tese analisa o projeto de integração dos índios concebido pelos Secretários de Estado do reinado de dom José I, atendendo ao Alvará de 8 de maio de 1758 que ampliou para todo o Brasil as leis de 6 e 7 de junho de 1755. Essa legislação, complementada pelo Diretório dos Índios, determinou a liberdade desses povos, tornando-os súditos do rei de Portugal e restringindo o poder das ordens religiosas ao separar as esferas administrativas civis e eclesiásticas". (2013b, p. 20-21).

vii Etnografia intitulada "BORA VE QUEM PODE MAIS": Uma etnografia sobre o fazer política entre os Tupinambá de Olivença (Ilhéus, Bahia), defendida junto ao programa de Antropologia da Universidade Federal de Santa Catarina. Conheci Cinthia quando estava em campo, momento em que ela também se encontrava realizando sua pesquisa. A partir desse encontro, temos mantido diálogos constantes que ajudaram a compreender muitas das questões que dizem respeito ao estar na cultura entre os Tupinambá, abordados também em sua tese.

viii Em 2011, o IDEB da Escola Estadual Indígena Tupinambá de Olivença era de 1,3.

ix Até o presente os Tupinambá aguardam a demarcação.

x Aspecto também ressaltado por Rocha (2014).

xi Agradecemos a Felipe Ferreira Vander Velden por nos ter sugerido esta perspectiva, no momento da arguição da tese. 
Sobre os autores

José Valdir Jesus de Santana. Doutor em Antropologia Social pela Universidade Federal de São Carlos. Professor adjunto da Universidade Estadual do Sudoeste da Bahia (UESB), nos cursos de Ciências Sociais, Pedagogia e no Programa de Pós-Graduação em Relações Étnicas e Contemporaneidade. Coordenador dos Grupos de Pesquisa em Educação para as Relações Étnicoraciais: $\mathrm{O}$ que nos dizem as crianças? e Educação Escolar Indígena no Estado da Bahia: experiências entre os povos indígenas Tupinambá, Pataxó e Pataxó Hã Hã Hãe. Endereço eletrônico: santanavaldao@yahoo.com.br

Clarice Cohn. Doutora em Antropologia Social pela Universidade de São Paulo (USP). Pós-Doutorado pela Université Paris Ouest Nanterre La Défense. Docente no curso de Ciências Sociais da Universidade Federal de São Carlos e credenciada no Programa de Pós-Graduação em Antropologia Social desta mesma universidade. Coordena o Laboratório de Estudos e Pesquisas em Antropologia da Criança (LEPAC) e coordenou o Observatório da Educação Escolar Indígena da UFSCar (OEEI/UFSCar), pelo qual realizou e orientou diversas pesquisas e organizou eventos com o tema da educação indígena e da educação escolar indígena. Faz pesquisas com os Xikrin do Bacajá desde 1992, e atua como antropóloga e cidadã nas áreas de educação escolar indígena, crianças indígenas e direitos indígenas. Endereço eletrônico: clacohn@gmail.com

Recebido: 29.06 .18

Aprovado: 20.07.18 